\title{
Desenvolvimento da cultura do milho sob efeitos de diferentes profundidades de compactação do solo
}

\author{
Nayara Spricigo Labegalini ${ }^{1}$, Antonio Carlos Buchelt ${ }^{1}$, Lurian Andrade ${ }^{1}$, Samieli Camargo de \\ Oliveira $^{1}$, Luana Marques Campos ${ }^{1}$
}

${ }^{1}$ Universidade do Estado de Mato Grosso - UNEMAT, Alta Floresta, Mato Grosso, Brasil. E-mail: nayaraagro@ outlook.com,
antoniobuchelt@ hotmail.com, lurian.andrade@gmail.com, estrela_samy@hotmail.com, uanamarquescampos@hotmail.com

Recebido: 06/04/2016; Aceito: 04/07/2016

\section{RESUMO}

A compactação do solo determina, de certa maneira, as relações entre ar, água e temperatura, e estas influenciam praticamente em todas as fases do desenvolvimento vegetal. Nesse sentido, o objetivo do trabalho foi avaliar o efeito de diferentes profundidades de compactação, no desenvolvimento da cultura do milho. $\mathrm{O}$ delineamento experimental utilizado foi o de blocos inteiramente casualizados, com cinco tratamentos $(0,25,50,75$ e $100 \%$ de compactação) e quatro repetições totalizando 20 unidades experimentais. Essas unidades experimentais foram representadas por vasos de polipropileno com $18 \mathrm{~cm}$ de altura e volume de $6,7 \mathrm{dm}^{3}$. As características avaliadas foram: Altura de plantas, massa verde da parte aérea, massa seca da parte aérea, massa verde de raízes compactadas, massa seca de raízes compactadas, massa verde de raízes sem compactação, massa seca de raízes sem compactação. Os resultados evidenciaram que tanto o crescimento da parte aérea como o crescimento das raízes de milho são prejudicados pela compactação do solo.

Palavras-chave: Crescimento, raízes, Zea mays

\section{Maize development under effects of different soil compaction depths}

\begin{abstract}
Soil compaction determines the relationship between air, water and temperature, and these influencing practically all phases of plant development. In this sense, the objective of this study was to evaluate the effect of different depths of compression, in the development of maize plants. The experimental design was a randomized blocks, with five treatments $(0,25,50,75$ and $100 \%$ compression) and four repetitions totaling 20 experimental units. These experimental units represented by polypropylene pots of $18 \mathrm{~cm}$ height and volume of $6.7 \mathrm{dm}^{3}$. The characteristics evaluated were: plant height, shoot fresh mass, shoot dry mass, fresh mass of compacted roots, dry mass of compacted roots, fresh mass without compression roots, dry mass of roots without compression. The results showed that both shoot growth as the growth of maize roots were damaged by soil compaction.
\end{abstract}

Key words: Growth, roots, Zea Mays. 


\section{Introdução}

O milho (Zea mays) é um dos alimentos mais nutritivos e uma das culturas agrícolas mais cultivadas pelo homem; importante fonte de nutrientes para homens e animais. Além disso, é rico em carboidratos, proteínas, vitaminas e sais minerais. Devido à multiplicidade de aplicações, quer na alimentação humana, quer na alimentação animal, assume relevante papel socioeconômico, além de constituir-se em indispensável matéria-prima impulsionadora de diversificados complexos agroindustriais (DOURADO NETO; FANCELLI, 2004.)

A compactação altera as propriedades físicas do solo podendo causar redução no comprimento do sistema radicular e aumento no seu diâmetro, como consequência do aumento da resistência mecânica que as raízes têm que vencer para crescer (SANTOS et al., 2005). A compactação produzida na superfície do solo dificulta o desenvolvimento das raízes das plantas, o que resulta em dificuldades na absorção de água e nutrientes (NOGUEIRA; MANFREDI, 1983), e consequentemente, prejudica a troca gasosa com o ambiente, induzindo assim à uma possível queda de produtividade.

Dentre os fatores primordiais para a germinação estão a umidade, a temperatura e a aeração do solo, entretanto estes fatores são diretamente influenciados pelo estado de compactação do solo ao redor da semente (MODOLO et al.,2011). Sendo a compactação um sério problema para os solos agrícolas, seu estudo é intenso, bem como também a busca por medidas que permitam a comparação entre os diferentes solos (ALMEIDA et al., 2008). O objetivo do trabalho foi avaliar o efeito de diferentes profundidades de compactação, no desenvolvimento da cultura do milho.

\section{Material e Métodos}

$\mathrm{O}$ experimento foi conduzido em casa de vegetação na Universidade do Estado de Mato Grosso UNEMAT, Campus universitário de Alta Floresta MT, no ano de 2015. As coordenadas geográficas do local são $09^{\circ} 51^{\prime} 42^{\prime \prime}$ S e $56^{\circ} 04^{\prime} 07^{\prime \prime}$ W e com altitude média de $283 \mathrm{~m}$.

O clima da região é tropical chuvoso (tipo Awi segundo Köppen), com estação climática bem definida, estiagem rigorosa e período chuvoso intenso. A temperatura varia de 18 a $40{ }^{\circ} \mathrm{C}$, apresentando média de $26^{\circ}$ C. A pluviosidade pode atingir médias extremamente altas, podendo ultrapassar $2.800 \mathrm{~mm}$ anuais.

O solo utilizado foi um Latossolo Vermelho Amarelo Distrófico Distrófico (EMBRAPA, 2013), que apresentou as seguintes características químicas e físicas: $\mathrm{pH}_{\mathrm{H} 2 \mathrm{O}}=5,51 ; \mathrm{P}_{\text {(Mehlich) }}=0,15 \mathrm{mg} \mathrm{dm}^{-3} ; \mathrm{K}_{\text {(Mehlich) }}$
$=59,7 \mathrm{mg} \mathrm{dm}^{-3} ; \mathrm{Ca}=1,27 \mathrm{cmol}_{\mathrm{c}} \mathrm{dm}^{-3} ; \mathrm{Mg}=0,55 \mathrm{cmol}_{\mathrm{c}}$ $\mathrm{dm}^{-3} ; \mathrm{Al}=0,13 \mathrm{cmol}_{\mathrm{c}} \mathrm{dm}^{-3} ; \mathrm{H}+\mathrm{Al}=3,15 \mathrm{cmol}_{\mathrm{c}} \mathrm{dm}^{-3} ;$ CTC $=5,1 \mathrm{cmol}_{\mathrm{c}} \mathrm{dm}^{-3}$; saturação por bases de $38,5 \%$; argila $=29,3 \%$; silte $=14,4 \%$ e areia total $=56,3 \%$.

O delineamento experimental utilizado foi o de blocos inteiramente casualizados, com cinco tratamentos $(0,25,50,75$ e $100 \%$ de compactação) e quatro repetições totalizando 20 unidades experimentais. Essas unidades experimentais foram representadas por vasos de polipropileno com $18 \mathrm{~cm}$ de altura e volume de $6,7 \mathrm{dm}^{3}$. No primeiro tratamento $(0 \%)$ os vasos foram preenchidos de terra sem nenhuma compactação. Os demais tratamentos foram compactados com uma densidade de $1,5 \mathrm{~kg} \mathrm{dm}^{-3}$, sendo que os tratamentos $(25 \%, 50 \%$ e $75 \%)$ foram compactados, respectivamente, 25,50 e $75 \%$ do seu volume na base dos vasos e o restante do volume foi completado com terra sem compactação, diferindo, portanto, a compactação em profundidade. No tratamento $100 \%$ o volume do vaso foi totalmente compactado.

Antes de serem acondicionadas nos vasos, as amostras de terra que apresentavam densidade aparente natural de $1,0 \mathrm{~kg} \mathrm{dm}^{-3}$ foram coletadas na camada de 0 $20 \mathrm{~cm}$. Em seguida passaram em peneira com malha de $4 \mathrm{~mm}$ e secas ao ar, sendo adicionados $13 \%$ de peso em água com a finalidade de facilitar o processo de compactação; esta foi realizada com o auxilio de um malho de madeira de modo que atingisse a densidade desejada. A adubação de semeadura utilizada foi 1000 $\mathrm{kg} \mathrm{ha}^{-1}$ do formulado 4-14-8. Aos 19 dias após a emergência (DAE) foi realizada adubação de cobertura com $500 \mathrm{~kg} \mathrm{ha}^{-1}$ com o formulado 20-00-20. A semeadura foi realizada no dia 07 de outubro de 2015 , foram semeadas cinco sementes por vaso do cultivar AG 1050 e após a emergência das plântulas realizou-se o desbaste, deixando apenas duas por vaso.

Aos 35 dias avaliou-se altura de plantas (AP) com auxílio de régua graduada. Realizou-se a separação de parte aérea e raízes; na avaliação das raízes dos tratamentos $(25 \%, 50 \%$ e $75 \%)$ foram separadas raízes do solo com aplicação de compactação e raízes do solo preenchido (sem compactação) (camada compactada e camada superior sem compactação). As raízes foram lavadas em água corrente, colocadas em pacotes de papel Kraft e pesadas para obtenção de massa fresca da parte aérea (MFPA), massa fresca das raízes desenvolvidas na camada compactada (MFRC) e massa fresca das raízes desenvolvidas na camada sem compactação (MFRSC). O conjunto foi acondicionado em estufa de ventilação forçada a $65{ }^{\circ} \mathrm{C}$ por $48 \mathrm{~h}$, para posterior determinação da massa seca de parte aérea (MSPA), massa seca das raízes desenvolvidas na camada compactada (MSRC) e massa seca das raízes desenvolvidas na camada sem compactação (MSRSC). 
Os resultados obtidos foram submetidos à análise de variância e teste de regressão a $5 \%$ de probabilidade pelo programa SISVAR ${ }^{\circledR}$ (FERREIRA, 2008).

\section{Resultados e Discussão}

A compactação do solo nas diferentes profundidades obteve um decréscimo linear em relação ao crescimento das plantas (Figura 1), sendo que o tratamento $100 \%$ resultou em plantas com alturas menores $(15,25 \mathrm{~cm})$. Tal fato está relacionado com a densidade do solo utilizada nesse tratamento que foi de $1,5 \mathrm{~kg} \mathrm{dm}^{-3}$. Solos compactados inibem o desenvolvimento do sistema radicular pois inibem a absorção de água e de nutrientes que são necessários no desenvolvimento da parte aérea e radicular da planta. Em consequência essa baixa absorção de água e nutriente resulta em menor desenvolvimento da planta.

A altura da planta nos tratamentos $(25 \%, 50 \%, 75 \%$ e $100 \%$ ) foi reduzida, respectivamente, em 12, 24, 28 e $74 \%$ quando comparado com o tratamento sem compactação (0\%). Portanto, seja no tratamento com $100 \%$ compactação ou compactação em profundidade no caso dos tratamentos $(25 \%, 50 \%$ e $75 \%)$ observou-se menor desenvolvimento das plantas na cultura.

Foloni et al. (2003) verificaram que o efeito da compactação resultou na redução do crescimento aéreo das plantas de milho, em média, aproximadamente $20 \%$, após 40 dias de cultivo sob 1,69 $\mathrm{Mg} \mathrm{m}^{-3}$ de impedância mecânica do solo em subsuperfície.

Gediga (1991) verificou que a matéria seca da parte aérea do milho foi incrementada em $10 \%$ quando aumentou-se a densidade do solo de 1,45 para $1,70 \mathrm{Mg}$ $\mathrm{m}^{-3}$ em subsuperfície.

Resultados contraditórios em relação a esse parâmetro, apresentados na literatura, estão relacionados com a textura do solo, estádio de desenvolvimento das plantas e a condição de cultivo. Bennie (1996) ressalta a dificuldade de generalizar conclusões quanto ao desenvolvimento das plantas em solos compactados.

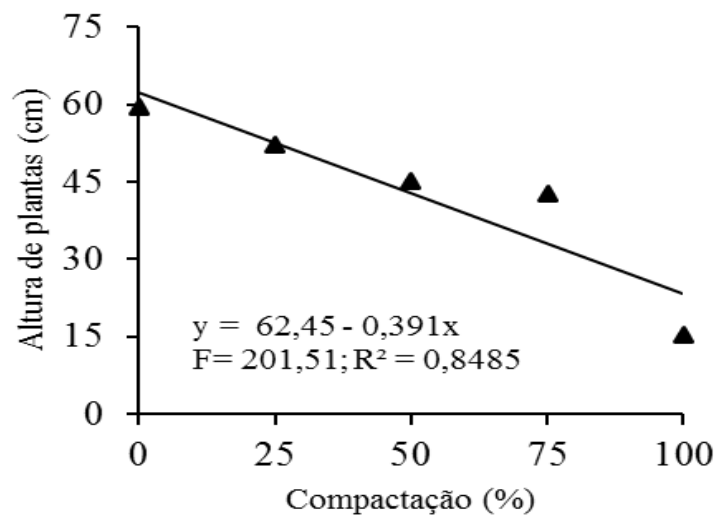

Figura 1 - Comportamento da variável altura de planta (AP) sob efeitos de diferentes profundidades de compactação, Alta Floresta, MT, 2016

Pelos resultados obtidos, quanto ao desenvolvimento da cultura do milho sob efeitos de diferentes profundidades de compactação do solo, observou-se relação funcional significativa entre todas as variáveis, exceto para massa verde de raízes sem compactação (MSRC) (Tabela 1). Considerando que o aumento da compactação resultou em menor desenvolvimento das plantas. Estes resultados indicam o efeito negativo da compactação do solo no crescimento das plantas.

Para a massa fresca da parte aérea (Figura 2), o tratamento com ausência de compactação resultou em maior desenvolvimento da planta, apresentando 187,5 g, enquanto que a profundidade de compactação de $100 \%$ apresentou menor desenvolvimento, com apenas $4,5 \mathrm{~g}$ de MFPA seguido do tratamento com $75 \%, 50 \%$ e $25 \%$ com valores respectivos de 76,25, 110,00 e 133,75 g. Guimarães et al. (2013) na cultura do milheto observaram uma redução da MFPA em média de $41 \%$, conforme o aumento da densidade do solo.

O nível de compactação de $100 \%$ resultou em menor acúmulo de massa seca da parte aérea (Figura 3), com $0,78 \mathrm{~g}$, sendo esse valor $96 \%$ menor que apresentado no tratamento sem compactação. Nos tratamentos com 25, 50 e $75 \%$ de compactação, a redução na massa seca foi de 15,36 e $65 \%$, respectivamente.

Tabela 1. Altura de plantas (AP), massa verde da parte aérea (MVPA), massa seca da parte aérea (MSPA), massa verde de raízes compactadas (MVRC), massa seca de raízes compactadas (MSRC), massa verde de raízes sem compactação (MVRSC), massa seca de raízes sem compactação (MSRSC). Alta Floresta-MT, 2016

\begin{tabular}{|c|c|c|c|c|c|c|c|}
\hline Tratamentos & $\begin{array}{l}\text { AP } \\
\mathrm{cm}\end{array}$ & $\begin{array}{l}\text { MVPA } \\
\mathrm{g}\end{array}$ & $\begin{array}{l}\text { MSPA } \\
\mathrm{g}\end{array}$ & $\begin{array}{l}\text { MVRC } \\
\mathrm{g}\end{array}$ & $\begin{array}{l}\text { MSRC } \\
\mathrm{g}\end{array}$ & $\begin{array}{l}\text { MVRSC } \\
\mathrm{g}\end{array}$ & $\begin{array}{l}\text { MSRSC } \\
\text { G }\end{array}$ \\
\hline $0 \%$ & 59,38 & 187,50 & 21,61 & 0,00 & 0,00 & 82,50 & 18,09 \\
\hline $25 \%$ & 52,13 & 133,75 & 18,40 & 16,25 & 6,25 & 50,00 & 18,61 \\
\hline $50 \%$ & 45,16 & 110,00 & 13,77 & 13,75 & 3,90 & 36,25 & 11,27 \\
\hline $75 \%$ & 42,63 & 76,25 & 7,67 & 16,25 & 3,33 & 21,25 & 7,24 \\
\hline $100 \%$ & 15,25 & 4,50 & 0,78 & 4,50 & 2,46 & 0,00 & 0,00 \\
\hline Valor de F & $59,37 * *$ & $17,27 * *$ & $18,27 * *$ & $4,13^{*}$ & $1,44 \mathrm{~ns}$ & $30,21 * *$ & $4,72 *$ \\
\hline CV $(\%)$ & 10,15 & 32,01 & 31,46 & 72,28 & 118,55 & 29,71 & 65,01 \\
\hline
\end{tabular}

**, * e ns: Significativo a 1\%; $5 \%$ de probabilidade de erro e não significativo, respectivamente. 
Para a cultura do arroz a massa seca da parte aérea foi reduzida conforme o aumento da densidade do solo, reduzindo $35,8 \%$, em consequência do aumento de $0,5 \mathrm{~g}$ $\mathrm{cm}^{-3}$ da densidade do solo (GUIMARÃES; MOREIRA, 2001).

$\mathrm{Na}$ massa verde de raiz compactada (Figura 4) houve ajuste do modelo quadrático sendo que a partir de $53,35 \%$ de compactação começou a ocorrer decréscimo no desenvolvimento das raízes. Silva et al (2014) observaram para a cultura da soja que houve aumento na MSR na camada superior conforme o grau de compactação, indicando que houve restrição de crescimento em profundidade e as raízes não se aprofundaram. Rosolem et al (1994) observaram que também em raízes de soja o aumento da densidade da camada subsuperficial induziu à diminuição significativa na massa seca das raízes.

Observou-se na massa verde de raiz sem compactação (Figura 5) que o tratamento ausente de compactação apresentou o maior acúmulo de raízes sob grande influência dos níveis de compactação, demonstrando assim que as raízes são sensíveis aos níveis de compactação infligidos no solo.

No acúmulo de massa seca de raízes sem compactação (Figura 6), o tratamento com 25\% apresentou $18,61 \mathrm{~g}$ e o de ausência com $18.09 \mathrm{~g}$.

$\mathrm{Na}$ avaliação visual do experimento observou-se que nos tratamentos com $25 \%, 50 \%$, e $75 \%$ que tiveram o restante do seu volume preenchido por solo solto, as raízes apresentaram maior quantidade de radicelas; já na parte compactada do vaso houve grande concentração de raízes grossas que circundavam a camada de solo compactado mas apresentavam baixa penetração nessa camada, com baixa concentração de radicelas. Desta forma também observado por Müller et al (2011) cujo aumento da densidade do solo provocou aumento do diâmetro radicular médio na camada compactada para o tremoço branco, aveia preta e aveia branca.
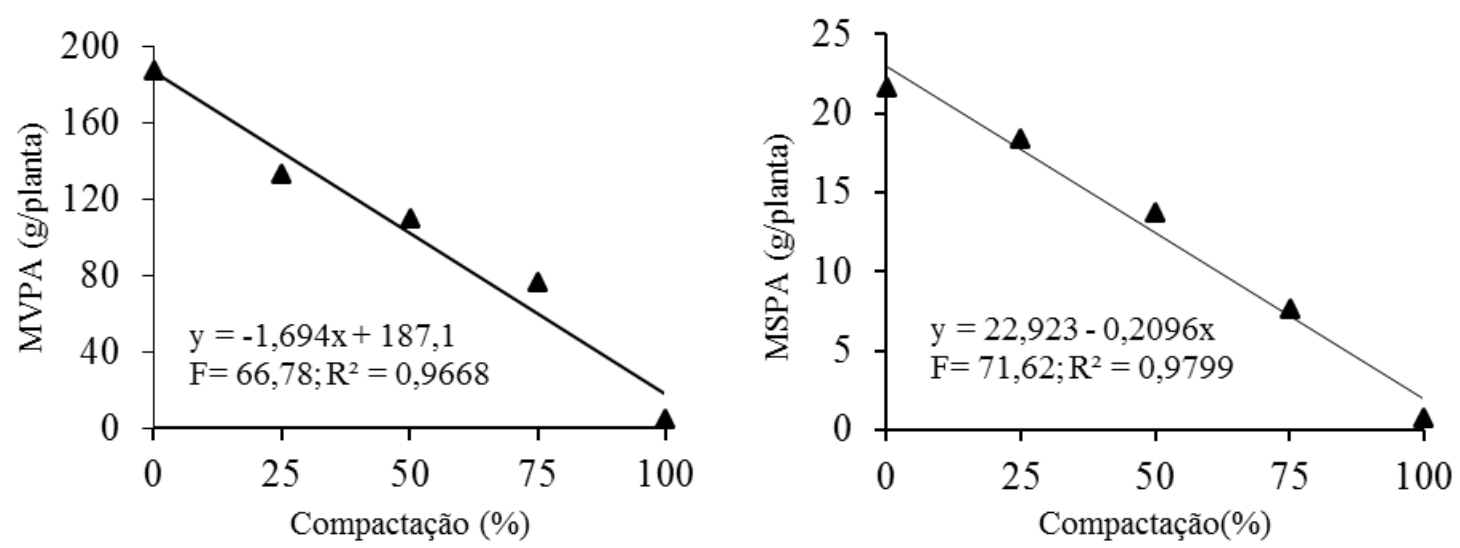

Figura 2 e 3 - Massa verde da parte aérea (MVPA) e massa seca da parte aérea (MSPA) das plantas de milho sob efeitos de diferentes profundidades de compactação, Alta Floresta, MT, 2016
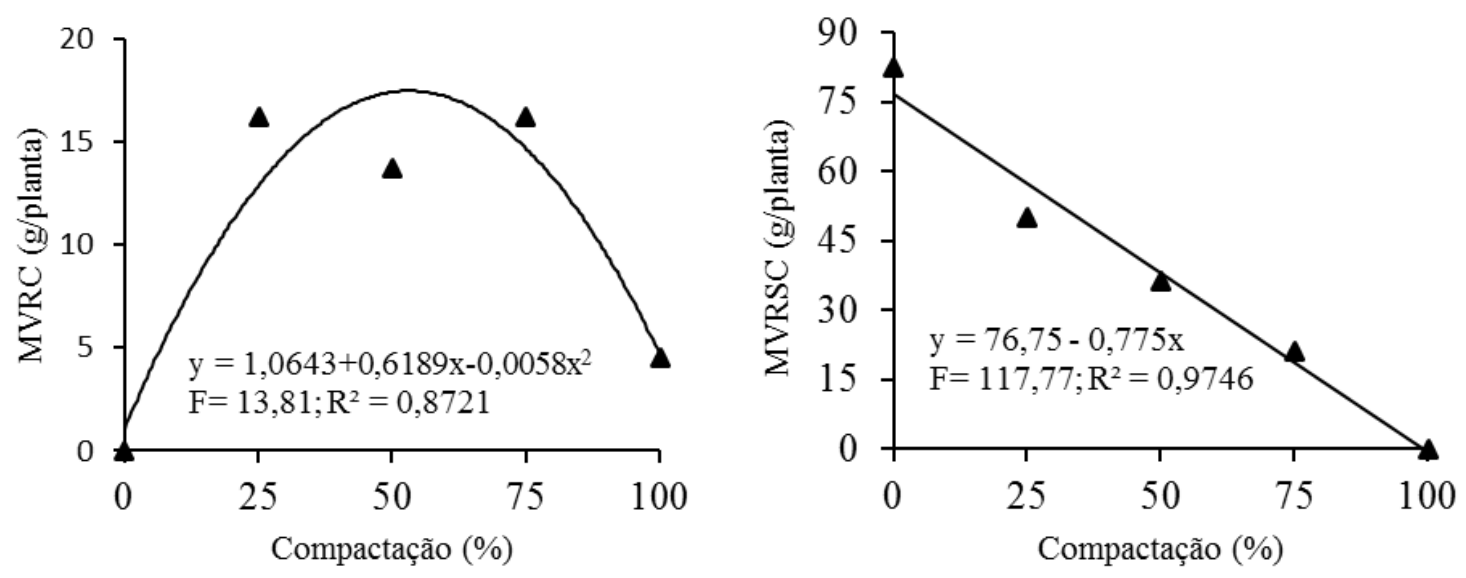

Figura 4 e 5 - Massa verde das raízes na camada compactada (MVRC) e massa verde das raízes na camada sem compactação (MVRSC) das plantas de milho sob efeitos de diferentes profundidades de compactação, Alta Floresta, MT, 2016. 


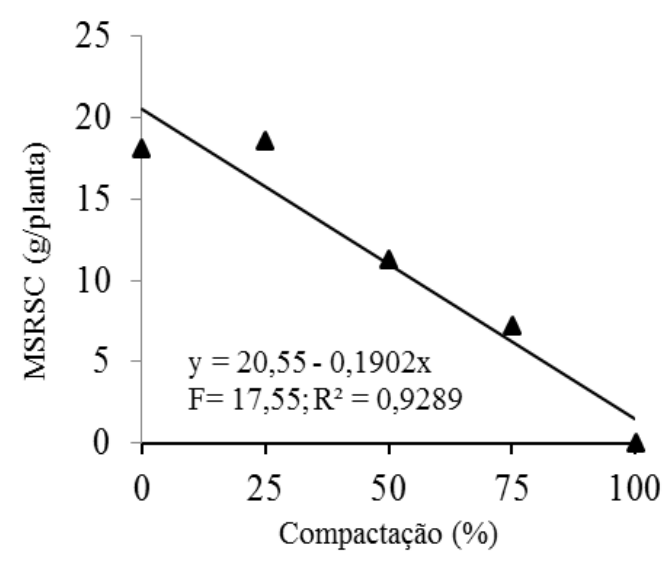

Figura 6 - Massa seca das raízes de milho na camada sem compactação (MSRSC) sob efeitos de diferentes profundidades de compactação, Alta Floresta, MT, 2016.

\section{Conclusões}

$\mathrm{Na}$ cultura do milho, o crescimento aéreo assim como o crescimento radicular são igualmente prejudicados pela compactação do solo

\section{Referências Bibliográficas}

ALMEIDA, C. X.; CENTURION, J. F.; FREDDI, O. S.; JORGE, R. F.; BARBOSA, J. C. Funções de pedotransferência para a curva de resistência do solo à penetração. Revista Brasileira de Ciência do Solo, Jaboticabal-SP, v. 32, n. 6, p. 2235-2243, 2008.

BENNIE, A. T. P. Growth and mechanical impedance. In: WAISEL, Y.; ESHEL, A.; KAFKAFI, U. Plant roots. $2^{\text {nd }}$ ed. New York-USA: M. Dekker, 1996. p. 453-470.

FANCELI, A. L.; DOURADO NETO, D. D. Produção de milho. $2^{a}$ ed. Guaíba-RS: Agropecuária, 2004. 360 p.

FERREIRA, D. F. SISVAR: Um programa para análises e ensino de estatística. Revista Científica Symposium, LavrasMG, v. 6, n. 2, p. 36-41, 2008

FOLONI, J. S. S.; CALONEGO, J. C.; LIMA, S. L. Efeito da compactação do solo no desenvolvimento aéreo e radicular de cultivares de milho. Pesquisa Agropecuária Brasileira, Brasília-DF, v. 38, n. 8, p. 947-953, 2003.
GEDIGA, K. Influence of subsoil compaction on the uptake of $45 \mathrm{Ca}$ from the soil profile and on maize yield. Soil and Tillage Research, Amsterdam, v. 19, n. 2, p. 351- 355, 1991.

GUIMARÃES, C. M.; MOREIRA, J. A. A. Compactação do solo na cultura do arroz de terras altas. Pesquisa Agropecuária Brasileira, Brasília-DF, v. 36, n. 4, p. 703-707, 2001 .

GUIMARÃES, C. V.; ASSIS, R. L.; SIMON, G. A.; PIRES, F. R.; FERREIRA, R. L.; SANTOS, D. C. Desempenho de cultivares e híbridos de milheto em solo submetido a compactação. Revista Brasileira de Engenharia Agrícola e Ambiental, Campina Grande-PB, v. 17, n. 11, p. 1188-1194, 2013.

MODOLO, A. J.; TROGELlO, E.; NUNES, A. L.; SILVEIRA, J. C. M.; KOLLING, E. M. Efeito da compactação do solo sobre a semente no desenvolvimento da cultura do feijão. Acta Scientiarum Agronomy, Maringá-PR, v. 33, n. 1, p. 89-95, 2011.

MÜLLER, M. M. L.; CECCON, G.; ROSOLEM C. A. Influência da compactação do solo em subsuperfície sobre o crescimento aéreo e radicular de plantas de adubação verde de inverno. Revista Brasileira Ciências Solo, Brasília-DF, v. 25, n. 1, p. 531-538, 2011.

NOGUEIRA, S. S. S.; MANFREDINI, S. Influência da compactação do solo no desenvolvimento da soja. Pesquisa Agropecuária Brasileira, Campina Grande-PB, v.18, n. 9, p. 973-976, 1983.

ROSOLEM, C. A.; ALMEIDA, A. C. S.; SACRAMENTO, L. V. S. Sistema radicular e nutrição da soja em função da compactação do solo. Bragantia, Campinas-SP, v. 53, n. 2, p. 259-266, 1994.

SANTOS, G. A.; SOUZA, C. A. S.; DIAS JUNIOR, M. S.; FURTINI NETO, A. E.; GUIMARÃES, P. T. G. Diferentes graus de compactação e fornecimento de fósforo influenciando no crescimento de plantas de milho (Zea mays L.) cultivadas em solos distintos. Ciência Agroecológica, Lavras-MG, v. 29, n. 4, p.740-752, 2005.

SILVA, F. R.; ALBUQUERQUE, J. A.; COSTA, A. Crescimento inicial da cultura da soja em Latossolo Bruno com diferentes graus de compactação. Revista Brasileira Ciências Solo. Viçosa-MG, v. 38, n. 1, p. 1731-1739, 2014. 